\title{
Public health benefits of hair-mercury analysis and dietary advice in lowering methylmercury exposure in pregnant women
}

\section{Citation}

Kirk, Line E., Jan S. Jørgensen, Flemming Nielsen, and Philippe Grandjean. 2017. “Public Health Benefits of Hair-Mercury Analysis and Dietary Advice in Lowering Methylmercury Exposure in Pregnant Women." Scandinavian Journal of Public Health 45 (4) (April 6): 444-451. doi:10.1177/1403494816689310.

\section{Published Version}

$10.1177 / 1403494816689310$

\section{Permanent link}

http://nrs.harvard.edu/urn-3:HUL.InstRepos:37221738

\section{Terms of Use}

This article was downloaded from Harvard University's DASH repository, and is made available under the terms and conditions applicable to Open Access Policy Articles, as set forth at http:// nrs.harvard.edu/urn-3:HUL.InstRepos:dash.current.terms-of-use\#OAP

\section{Share Your Story}

The Harvard community has made this article openly available.

Please share how this access benefits you. Submit a story.

Accessibility 


\title{
Public health benefits of hair-mercury analysis and dietary advice in lowering methylmercury exposure in pregnant women
}

\author{
LINE E KIRK $^{1,2}$, JAN S JøRGENSEN ${ }^{3}$, FLEMMING NIELSEN $^{1} \&$ PHILIPPE \\ GRANDJEAN ${ }^{1,4}$
}

${ }^{1}$ Department of Public Health, University of Southern Denmark, Odense, Denmark, ${ }^{2}$ OPEN, Odense Patient Data Explorative Network, Odense University Hospital, Odense, Denmark, ${ }^{3}$ Department of Gynaecology and Obstetrics, Odense University Hospital, Odense, Denmark,

${ }^{3}$ Department of Environmental Health, Harvard School of Public Health, Boston MA, USA.

Correspondence: P Grandjean, Environmental Medicine, University of Southern Denmark, J.B.Winsloewsvej 17A, DK-5000 Odense C, Denmark. Email: pgrand@sdu.dk

Shortened running title: Lowering mercury exposure in pregnant women

Word count: 3094 (excl. abstract and references) 


\begin{abstract}
Aim: To evaluate whether a public health intervention using focused dietary advice combined with a hair-mercury analysis can lower neurotoxic methylmercury exposure among pregnant women, without decreasing overall seafood intake. Methods: At the antenatal clinic at a Danish university hospital, a total of 146 pregnant women were consecutively recruited at the initial ultrasound scan. Dietary advice was provided on avoiding methylmercury exposures from large, predatory fish, and a hair sample from each participant was analysed for mercury, with the results being communicated shortly thereafter to the women. A dietary questionnaire was filled in. Follow-up three months later included a dietary questionnaire and a repeat hair-mercury analysis. Results: In the follow-up group, 22 percent had hair-mercury concentrations above a safe limit of $0.58 \mu \mathrm{g} / \mathrm{g}$ at enrolment, decreasing to 8 percent three months later. Average hair-mercury concentrations decreased by 21 percent. However, total seafood intake remained at the same level after three months. Conclusions: Elevated exposure to methylmercury among pregnant women is an important public health concern in Denmark. The observed lowering of hair-mercury concentrations associated with dietary advice corresponds to a substantial public health benefit that likely makes such intervention highly profitable.
\end{abstract}

Key Words: Intervention, methylmercury, pregnant women, prenatal exposure, intervention, costbenefit evaluation, seafood diet 


\section{Introduction}

In a recent statement, an international society of gynaecologists and obstetricians recommended that health professionals make environmental public health part of health care and champion environmental justice [1]. Among environmental chemicals that may adversely affect fetal development, methylmercury is of global public health concern [2,3]. Methylmercury is the most important mercury species in the environment where it is bioaccumulated in the muscle tissue of large, long-lived predatory fish, such as swordfish, shark and tuna; seafood is therefore the main source of exposure in humans [2]. While seafood provides nutrients essential for foetal development [4], elevated methylmercury exposure can cause developmental neurotoxicity and associated losses of IQ points [2]; the societal costs in the EU from an annual loss of more than 600,000 IQ points have been calculated to be about $€ 8-9$ billion per year [5]. Accordingly, public health interventions to limit methylmercury exposures should focus on avoidance of fish known to be high in mercury [6], while avoiding simplified advisories that may scare women from eating otherwise healthy seafood [7].

Nudging can be a useful approach to public health and dietary interventions [8], and the present study relies on measurement of individual exposure levels to promote low-mercury seafood among pregnant women. Methylmercury is the predominant mercury species in hair, and in rare cases, mercury vapour may result in external contamination. Hair-mercury analysis is a non-invasive and inexpensive method that is highly advantageous for population studies [6, 9]. We have previously used hair-mercury measurements as an indicator of recent methylmercury exposure after a revised seafood advisory [10], and an elevated hair-mercury result seems to motivate a subject to abstain from eating large, predatory fish [9]. As prenatal methylmercury exposure is the main public health concern, a targeted intervention needs to reach pregnant (or 
would-be pregnant) women. We therefore used individual hair-mercury analyses to motivate pregnant women to follow dietary guidelines with a view to limiting methylmercury exposures from contaminated seafood. Recommended limits for hair-mercury concentrations vary. Even the lowest official limit, i.e., $1.0 \mu \mathrm{g} / \mathrm{g}$ hair used by the U.S. Environmental Protection Agency [11], does not take into the impact of exposure misclassification [12] nor genetic predisposition to methylmercury toxicity [13]. An updated calculation suggests a more protective exposure limit of about $0.58 \mu \mathrm{g} / \mathrm{g}$ hair [12], and this limit was applied in an EU-wide comparison study [5] and in the present study as well.

The study was carried out in Denmark, where hair-mercury concentrations in women are known to be higher than those in neighbouring countries $(37 \%$ exceed a safe limit in Denmark, as compared to $28 \%$ in Norway and Sweden); assuming that exposures are similar in pregnant women, prevention of excess exposures in Denmark were estimated to represent an annual value of approximately $€ 100$ million [5]. As mercury contamination of seafood cannot be reduced in the short term, public health interventions must focus on dietary habits. We therefore provided dietary advice to pregnant women and used hair-mercury analysis to nudge the women with elevated exposures to avoid contaminated fish without reducing the total seafood intake.

\section{Methods}

Participants and procedure

The study population comprised 146 pregnant women consecutively recruited from the antenatal clinic at Odense University Hospital (OUH) in connection with the initial ultrasound scan for prenatal screening and ultrasound scan at pregnancy weeks 11-14. During the 3-month recruitment period, two strategies were used to contact the newly pregnant women. Written information was 
sent by mail to 518 women with an appointment within the recruitment period, but only $40(8 \%)$ responded and agreed to participate. Many of these women participated in bi-weekly group information meetings before the scan, where 25 more were recruited. Additionally, 223 women were approached at the ward before the scan, and 81 agreed to participate (36\%), thus bringing the total number of participants to 146.

\section{Questionnaire}

At enrolment, participants completed a questionnaire on personal data (name, telephone number, weight and height), gestational week, frequency of fish intake during the past 4 weeks (total seafood consumption, marine fish, shellfish, predatory fish and freshwater fish) with the following response options: "several times/day, daily, several times/week, once a week, two-three times within 4 weeks or never". Examples of the most common forms of edible fish were given. We also asked about dental work that involved removal of amalgam fillings and about potential mercury exposure at work. In addition we asked about natural hair colour and structure, as well as treatment (e.g. permanent) of the hair, as these factors can affect mercury concentrations [14].

\section{Intervention and follow-up}

Participants received both oral and written dietary advice. The focus was on the benefits of eating fish, as well as preventing mercury exposure, especially from predatory fish. We took into account the positive associations between maternal fish intake during pregnancy and developmental scores demonstrated in Danish children [15] and the advice from the Danish Veterinary and Food Administration for pregnant women to eat $350 \mathrm{~g}$ of fish per week, while avoiding cuts from predatory fish and more than one can of tuna per week [16]. 
Hair samples from the back of the head, corresponding to the thickness of a match, were cut as close to the scalp as possible. Participants who wished to be informed about the results of their hair sample (only one declined) were provided this information by secure e-mail, or results were mailed to the family doctor, as chosen by each woman. If the hair-mercury concentration was $>0.5 \mu \mathrm{g} / \mathrm{g}$, participants were again advised to avoid eating large predatory fish.

After enrolment and initial hair sampling, participants received a stamped and addressed envelope, containing a copy of the questionnaire and instructions to collect a follow-up hair sample. Four months later, participants were reminded to complete the questionnaires, cut a hair sample and return the envelope provided. Follow-up data was received from 86 women (59\%), with mean follow-up time being $125+13$ days.

\section{Mercury analysis}

We used a 1-cm hair segment closest to the scalp (Figure 1) and performed the analysis using Direct Mercury Analyzer (DMA-80, Milestone Inc, Sorrisole, Italy). The same laboratory carried out the analyses of Danish samples in the EU-wide study [5]. The 1-cm samples reflect mercury deposited approximately 30-60 days prior to collection (the most recent 30 days of growth has not yet emerged above the scalp) [17]. Standardized analytical quality-control procedures included an internal control in each series of analyses and regular participation in laboratory comparison programs. The laboratory imprecision is below $4 \%$. The detection limit was $0.03 \mu \mathrm{g} / \mathrm{g}$, but none of the samples collected showed a hair-mercury concentration below this level.

\section{Statistical analysis}


To obtain variance homogeneity and normally distributed residuals, mercury concentrations were transformed using the natural logarithm and all estimates were converted to reflect relative percentage changes in hair-mercury concentrations. For parameters with skewed distributions, we used medians rather than averages. Predictor variables were: frequency of seafood intake (total seafood consumption, marine fish, shellfish, predatory fish and freshwater fish, all of which coded as less than once a week/at least once a week), age, body mass index (BMI), gestational week, and work in a dental clinic (yes/no). Age and gestational week were coded as higher or lower than the median. To identify significant confounders, we used a $\chi 2$-test within the group initially enrolled ( $\mathrm{n}=146)$ to compare the distribution of total seafood consumption $(<1$ or $\geq 1 /$ week) at different levels of gestational week and status of work in a dental clinic. For the smaller follow-up group with ( $\mathrm{n}=86$ ), distributions of mercury concentrations, age, BMI, gestational week and seafood consumption at enrolment were compared with distributions at follow-up, in order to identify potential confounders, using Wilcoxon signed rank sum test, paired $t$-test and McNemar's test.

Linear regression analyses were carried out to estimate effects on mercury concentrations, with the primary exposure predictor being seafood intake (both total and each of the four different types) and age, gestational week, and work in a dental clinic, included as potential confounders, as selected on basis of associations with mercury concentrations. All analyses were performed using Stata Statistical Software Release 14 (StataCorp, College Station, TX).

\section{Ethics}

The study was conducted in accordance with the Helsinki Declaration, and approval was obtained from The Regional Scientific Ethical Committees for Southern Denmark (S-20140135) and the Danish Data Protection Agency. All participants provided written informed consent. 
Study data were collected and managed using REDCap (Research Electronic Data Capture) hosted at SDU [18].

\section{Results}

At enrolment, the median hair-mercury concentration was $0.34 \mu \mathrm{g} / \mathrm{g}$. A total of $27(18.5 \%)$ and 4 (2.7\%) had hair-mercury concentrations above 0.58 and $1.0 \mu \mathrm{g} / \mathrm{g}$, respectively. Only five women (3.4\%) stated that they ate predatory fish once a week or more (Table I). In multiple regression analyses that included the four different fish types as predictors, only intake of marine fish showed a statistically significant association with the hair-mercury concentrations (Table II). Compared to those eating seafood less than once per week, subjects with more frequent intakes had hair-mercury concentrations that averaged 96\% (95\% CI: 57, 145; $<<0.001)$ higher. No association between total seafood consumption and gestational week $(\mathrm{p}=0.76)$ or work in dental clinic $(\mathrm{p}=0.66)$ was found, and adjustment for these parameters did not materially affect the association between seafood diet and hair-mercury.

The women participating in the follow-up had a higher initial hair-mercury concentration (median, 0.38) than those choosing not to participate (median, 0.30) (Mann-Whitney test, $p=$ 0.006). Thus, of women with a hair-mercury below or equal to $0.25 \mu \mathrm{g} / \mathrm{g}$, only $22(46 \%)$ participated in the follow-up, while that was true for $36(61 \%)$ of those with levels between 0.25 and $0.5 \mu \mathrm{g} / \mathrm{g}$, and for $28(72 \%)$ of those that exceeded $0.5 \mu \mathrm{g} / \mathrm{g}$.

The median hair-mercury concentration for follow-up group decreased from 0.38 at enrolment to $0.34 \mu \mathrm{g} / \mathrm{g}$ at follow-up $(\mathrm{p}<0.001)$ (Table I), despite the fact that only women with elevated concentrations had received specific advice on avoiding predatory fish. The median change in hair-mercury was $0.08 \mu \mathrm{g} / \mathrm{g}$, which corresponds to an average of $21 \%$ of the initial 
concentrations. At enrolment, $19(22.1 \%)$ of these women exceeded the limit of $0.58 \mu \mathrm{g} / \mathrm{g}$, as compared to only $7(8.1 \%)$ at follow-up. For women with mercury concentrations above $0.58 \mu \mathrm{g} / \mathrm{g}$ at enrolment, the median decrease was $0.22 \mu \mathrm{g} / \mathrm{g}$, i.e., $33 \%$ of their median initial concentration of $0.67 \mu \mathrm{g} / \mathrm{g}$. Likewise, at enrolment, $4(4.7 \%)$ of the follow-up participants had mercury concentrations above $1.0 \mu \mathrm{g} / \mathrm{g}$, while the maximum value at follow up was $0.91 \mu \mathrm{g} / \mathrm{g}$.

Seafood was consumed at a minimum of once a week by $66 \%$ at enrolment and $65 \%$ at follow-up ( $\mathrm{p}=0.83$ ). Predatory fish was eaten once a week or more only by 4 participants both before and after (Table I). However, a more detailed inspection of the questionnaire data showed that, at follow-up fewer women never ate marine fish or shellfish, while more women (69\%) now abstained from predatory fish than at the first examination (57\%). In multiple regression analyses, associations between mercury exposure and total seafood consumption $(\mathrm{p}<0.001$, data not shown) were statistically significant at enrolment. The correlation at the time of follow-up showed more scattering, with one woman showing an increased hair-mercury concentration from 0.57 to $0.91 \mu \mathrm{g} / \mathrm{g}$ at the follow-up, allegedly without changes in her recent seafood consumption.

\section{Discussion}

Elevated exposure to methylmercury from contaminated seafood constitutes a serious public health problem, and societal costs from developmental neurotoxicity in the EU has been estimated to approach $€ 10$ billion per year [5]. As mercury contamination of seafood cannot be minimized in the short term, the only feasible public health intervention must rely on some form of dietary advice. Despite advisories issued by national food agencies, methylmercury exposures remain elevated among pregnant women in reproductive age groups [5]. The body burden of methylmercury can be substantially reduced within a few months [11], and an intervention at the 
beginning of pregnancy therefore seems appropriate [19]. We provided dietary advice supplemented by a personal hair-mercury analysis to the target population.

Hair-mercury concentrations correlated well with the frequency of seafood consumption, with a doubling in the hair-mercury concentration for total seafood consumption at least once a week, as compared to those who were eating less. Despite the fact that the total seafood consumption was unchanged, mercury concentrations decreased significantly from enrolment to follow-up. Although a reduced methylmercury exposure at an unchanged overall seafood intake has not been reported before, our findings are in general agreement previous reports that dietary advice in regard to healthy, low-mercury food can result in decreased mercury concentrations $[10$, 20], and it may even result in increased fish intake without increased hair-mercury concentrations [21].

The methylmercury exposure among the participating pregnant women was lower than that reported for adult Danish women in a recent study [18]. The reason for this difference is unclear, but may involve the attention that pregnant women already pay to healthy diets. In addition, participants received general dietary counselling (without special focus on mercury) before answering the questionnaire. Only $3 \%$ of the pregnant women stated that they consumed predatory fish a minimum of once a week, thus apparently following the official guideline. The same was true at follow-up (Table I). However, demographical differences, including age and residence, may also play a role.

The dietary questionnaire was brief in order to secure as high a participation rate as possible and in respect of the public-health feasibility of conducting this type of intervention. Furthermore, dietary questionnaires are imprecise in estimating methylmercury exposure [22], and the same is true for more detailed questionnaires $[6,21]$, thus not justifying the risk that a lengthy 
questionnaire may deter some women from participating. Thus, the crude data obtained allow only an exploratory analysis of the association between seafood intake and hair-mercury. Still, a significant association was found between total seafood intake and hair-mercury at enrolment. On the other hand, intake of predatory fish was not a significant predictor, and an inconsistency may have occurred between actual and stated consumption. In addition, methylmercury has an elimination half-life in humans of about 45-60 days [23, 24], thus resulting in a delay in hairmercury concentrations as a response to dietary change. Further, the questionnaire aimed at providing reliable information about average consumption during the previous four weeks. However, this period corresponds to the segment of the hair under formation in the hair root at the time of hair sampling [17]. Thus, deviations from a straight correlation are to be expected as a result of temporal changes in dietary habits. Because the baseline testing took place towards the end of first trimester, a change in dietary habits may already have happened after pregnancy was recognized, and the baseline levels observed may for this reason be lower those of the general population. A related concern is that extrapolation to the general pregnant population may not be appropriate due to relatively low response rate and the fact that women, who participated in followup, had higher initial hair-mercury concentration than those choosing not to participate.

Taking these concerns into consideration, the change of $21 \%$ in the median hair-mercury concentration from enrolment to follow-up is nonetheless remarkable. As the 1-cm hair sample analysed at the 4-month follow-up represents the cumulated methylmercury during the third month after enrolment, a steady state would not have been reached. Assuming a dietary change soon after the enrolment and a constant low-level mercury intake after that, the follow-up sample would likely represent little more than half of the total change to be expected. Thus, the results therefore reflect a potential decrease of as much as $40 \%$. Further, the decrease among the 19 women with 
mercury concentrations $>0.58 \mu \mathrm{g} / \mathrm{g}$ at enrolment was closer to $30 \%$, thus suggesting an even greater benefit for highly-exposed women.

The median decrease in hair-mercury at follow-up was only $0.08 \mu \mathrm{g} / \mathrm{g}$. However, the longterm decrease would likely be about twice that level, and the results included many women with hair-mercury concentrations that were already well below the exposure limit of $0.56 \mu \mathrm{g} / \mathrm{g}$ at enrolment and who had no need to change their seafood habits. Thus, overall, this short-term follow-up study illustrates the feasibility and advantage of including a hair-mercury analysis along with dietary advice in obstetric practice.

The public health benefits from decreasing prenatal levels of methylmercury exposure are likely to be considerable [19]. Methylmercury is a well-documented developmental neurotoxicant $[2,3]$ that can lead to losses in Intelligence Quotient (IQ). The economic benefits from preventing such losses, in terms of lower school performance, educational attainment, and lifetime income, are substantial. Both in the US [25] and in Europe [5], calculations of indirect costs show high economic impacts. For Danish women, the EU-wide study [5] estimated the total benefit from preventing excess methylmercury exposure above $0.58 \mu \mathrm{g} / \mathrm{g}$ at approximately $€ 100$ million per year. The present study primarily reflects lower levels of exposure than in the EU study and may be difficult to extrapolate to the general Danish population. However, we observed that the percentage of children born by mothers with hair-mercury above 0.58 decreased from $22 \%$ to around $8 \%$ within a few months. While refraining from any detailed calculation, these results suggest that the benefit of the intervention could easily represent a value of many million Euros per year.

The expected public health benefits suggest that an intervention at a national scale and similar to the present study could prevent a large proportion of elevated prenatal exposures to 
methylmercury. Accordingly, the intervention would easily be cost-efficient, as the clinical and laboratory costs for each pregnancy would be unlikely to exceed $€ 50$ per pregnancy. Thus, screening for mercury exposure and dietary advice in Canada has been estimated to cost approximately $\$ 34$, or about $€ 24$ [19]. If focusing primarily on women with a high fish intake, especially of predatory fish and canned tuna [16], the relative profit would be even higher. The associated dietary advice may also increase intakes of essential seafood nutrients, thereby adding to the benefits [21]. Our findings therefore suggest a highly appropriate way to comply with the medical recommendation that reproductive and other health care professionals make prevention of exposure to environmental chemicals a priority [1].

\section{Conclusions}

This study confirms that methylmercury exposure among pregnant women is an important public health issue. In addition, focused dietary advice coupled with a hair-mercury analysis can motivate pregnant women to adjust their seafood diets to lower their methylmercury exposures significantly. By minimizing prenatal exposures to this neurotoxicant will promote early brain development. While the results of the present study may not necessarily be representative at a national or regional scale, the costs of initiating focused dietary counselling and hair-mercury analysis is likely to be highly cost-efficient and therefore deserves public health attention. Current evidence could potentially be extended if introduction of this procedure in prenatal health care is linked to a randomized controlled trial with and without counselling and/or hair analysis.

\section{Acknowledgments}


We wish to thank Ranja Bjerring at Environmental Medicine for mercury analyses, the staff at the antenatal clinic at Odense University Hospital, Nana Hyldig and Christina Vinter at the Department of Gynaecology and Obstetrics for their support.

\section{Declaration of conflicting interests}

The authors declare no conflict of interest.

\section{Funding}

The study was funded entirely from internal institutional budgets.

\section{References}

[1] Di Renzo GC, Conry JA, Blake J, DeFrancesco MS, DeNicola N, Martin JN, Jr., et al. International Federation of Gynecology and Obstetrics opinion on reproductive health impacts of exposure to toxic environmental chemicals. Int J Gynaecol Obstet 2015;131:219-25.

[2] Karagas MR, Choi AL, Oken E, Horvat M, Schoeny R, Kamai E, et al. Evidence on the human health effects of low-level methylmercury exposure. Environ Health Perspect 2012;120:799-806.

[3] Grandjean P, Landrigan PJ. Neurobehavioural effects of developmental toxicity. Lancet Neurol 2014;13:330-8.

[4] Sheehan MC, Burke TA, Navas-Acien A, Breysse PN, McGready J, Fox MA. Global methylmercury exposure from seafood consumption and risk of developmental neurotoxicity: a systematic review. Bull World Health Organ 2014;92:254-69F.

[5] Bellanger M, Pichery C, Aerts D, Berglund M, Castano A, Cejchanova M, et al. Economic benefits of methylmercury exposure control in Europe: Monetary value of neurotoxicity prevention. Environ Health 2013;12:3.

[6] Pouzaud F, Ibbou A, Blanchemanche S, Grandjean P, Krempf M, Philippe HJ, et al. Use of advanced cluster analysis to characterize fish consumption patterns and methylmercury dietary exposures from fish and other sea foods among pregnant women. J Expo Sci Environ Epidemiol 2010;20:54-68.

[7] Oken E, Kleinman KP, Berland WE, Simon SR, Rich-Edwards JW, Gillman MW. Decline in fish consumption among pregnant women after a national mercury advisory. Obstet Gynecol 2003;102:346-51.

[8] Bucher T, Collins C, Rollo ME, McCaffrey TA, De Vlieger N, Van der Bend D, et al. Nudging consumers towards healthier choices: a systematic review of positional influences on food choice. Br J Nutr 2016;115:2252-63. 
[9] Knobeloch L, Tomasallo C, Anderson H. Biomonitoring as an intervention against methylmercury exposure. Public Health Rep 2011;126:568-74.

[10] Weihe P, Grandjean P, Jorgensen PJ. Application of hair-mercury analysis to determine the impact of a seafood advisory. Environ Res 2005;97:200-7.

[11] National Research Council. Toxicological effects of methylmercury. Washington, DC: National Academy Press; 2000. xvii, 344 p. p.

[12] Grandjean P, Budtz-Jorgensen E. Total imprecision of exposure biomarkers: implications for calculating exposure limits. Am J Industr Med 2007;50:712-9.

[13] Julvez J, Grandjean P. Genetic susceptibility to methylmercury developmental neurotoxicity matters. Front Genet 2013;4.

[14] Yasutake A, Matsumoto M, Yamaguchi M, Hachiya N. Current hair mercury levels in Japanese: survey in five districts. Tohoku J Exp Med 2003;199:161-9.

[15] Oken E, Osterdal ML, Gillman MW, Knudsen VK, Halldorsson TI, Strom M, et al. Associations of maternal fish intake during pregnancy and breastfeeding duration with attainment of developmental milestones in early childhood: a study from the Danish National Birth Cohort. Am J Clin Nutr 2008;88:789-96.

[16] Danish Food Administration. Sådan begraenser du dit indtag af kviksølv fra fisk [How to limit your intake of mercury from fish, in Danish]. Copenhagen: Danish Food Administration; 2015.

[17] Grandjean P, Jorgensen PJ, Weihe P. Validity of mercury exposure biomarkers. In: Wilson SH, Suk WA, editors. Biomarkers of Environmentally Associated Disease. Boca Raton: CRC Press/Lewis Publishers; 2002. p. 235-47.

[18] Harris PA, Taylor R, Thielke R, Payne J, Gonzalez N, Conde JG. Research electronic data capture (REDCap)--a metadata-driven methodology and workflow process for providing translational research informatics support. J Biomed Inform 2009;42:377-81.

[19] Gaskin J, Rennie C, Coyle D. Reducing Periconceptional Methylmercury Exposure: Cost-Utility Analysis for a Proposed Screening Program for Women Planning a Pregnancy in Ontario, Canada. Environ Health Perspect 2015;123:1337-44.

[20] Kim EH, Kim IK, Kwon JY, Kim SW, Park YW. The effect of fish consumption on blood mercury levels of pregnant women. Yonsei Med J 2006;47:626-33.

[21] Oken E, Guthrie LB, Bloomingdale A, Platek DN, Price S, Haines J, et al. A pilot randomized controlled trial to promote healthful fish consumption during pregnancy: the Food for Thought Study. Nutr J 2013;12:33.

[22] Oken E, Guthrie LB, Bloomingdale A, Gillman MW, Olsen SF, Amarasiriwardena CJ, et al. Assessment of dietary fish consumption in pregnancy: comparing one-, four- and thirty-sixitem questionnaires. Public Health Nutr 2014;17:1949-59.

[23] Yaginuma-Sakurai K, Murata K, Iwai-Shimada M, Nakai K, Kurokawa N, Tatsuta N, et al. Hair-to-blood ratio and biological half-life of mercury: experimental study of methylmercury exposure through fish consumption in humans. J Toxicol Sci 2012;37:123-30.

[24] Albert I, Villeret G, Paris A, Verger P. Integrating variability in half-lives and dietary intakes to predict mercury concentration in hair. Regul Toxicol Pharmacol 2010;58:482-9.

[25] Trasande L, Schechter C, Haynes KA, Landrigan PJ. Applying cost analyses to drive policy that protects children: mercury as a case study. Ann N Y Acad Sci 2006;1076:911-23. 


\section{Legend to figure}

Figure 1. A small lock of hair (thickness corresponding to a match) from the back of the neck is tied together with a cotton string, and lock is cut as close to the scalp as possible. The hair sample collected this way (insert) has hair strands aligned at the proximal end of the hair strands, thus allowing the laboratory to cut the $1-\mathrm{cm}$ segments that correspond to methylmercury exposures during recent months.

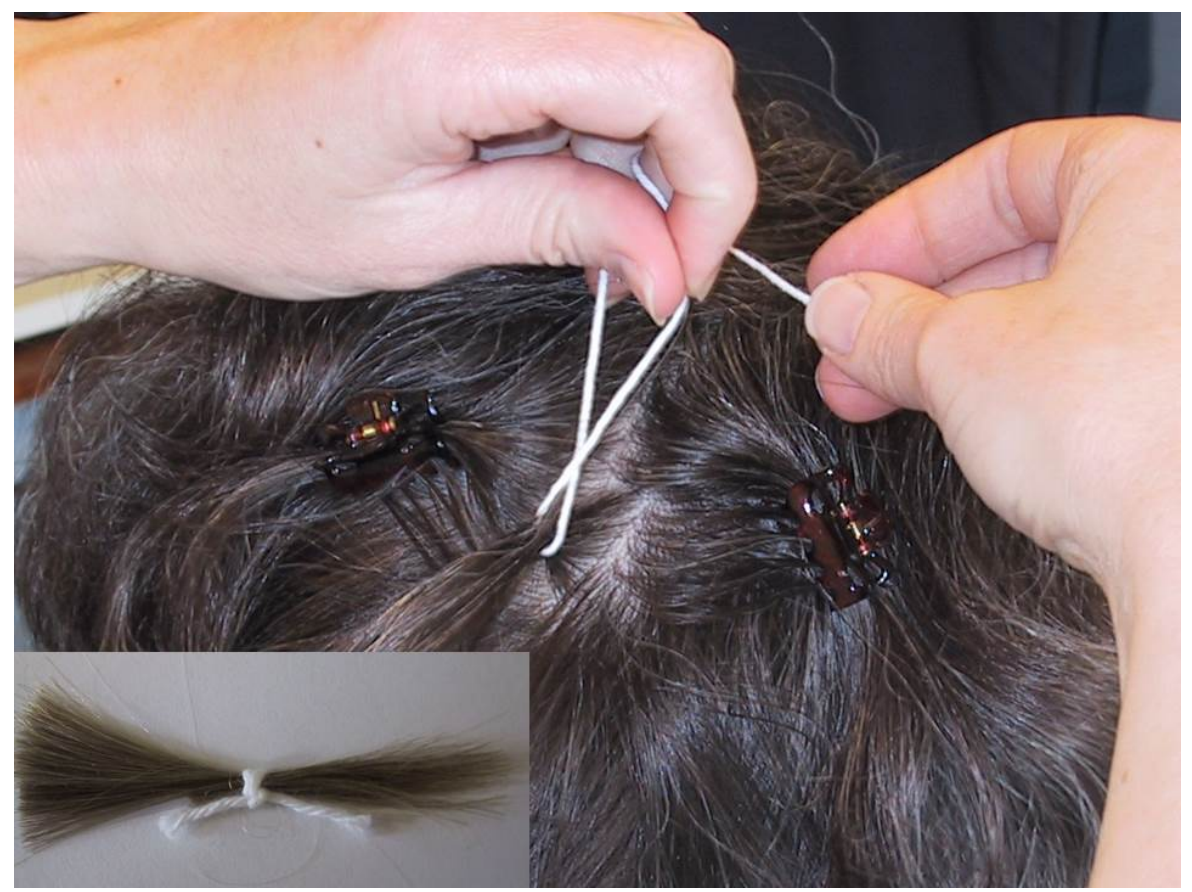


Table I. Baseline characteristics of the study cohort.

\begin{tabular}{|c|c|c|c|c|c|}
\hline & & \multirow{2}{*}{$\begin{array}{l}\text { All participants } \\
\text { At enrolment }\end{array}$} & \multicolumn{3}{|c|}{ Participants with follow-up } \\
\hline & & & At enrolment & At follow-up & Change \\
\hline & & $\mathrm{n}=146$ & $\mathrm{n}=86$ & $\mathrm{n}=86$ & $\mathrm{n}=86$ \\
\hline & & $\begin{array}{l}\text { Number / } \\
\text { percent }\end{array}$ & $\begin{array}{l}\text { Number / } \\
\text { percent }\end{array}$ & $\begin{array}{l}\text { Number / } \\
\text { percent }\end{array}$ & $p$-value \\
\hline $\mathrm{Hair}_{-\mathrm{Hg}^{\mathrm{a}}}$ & & $0.34(0.03,1.92)$ & $0.38(0.03,1.92)$ & $0.34(0.02,0.91)$ & $<0.001$ \\
\hline $\mathrm{Age}^{\mathrm{b}}$ & & $29.8 \pm 4.9$ & $30.4 \pm 4.6$ & $30.7 \pm 4.6$ & - \\
\hline $\mathrm{BMI}^{\mathrm{b}, \mathrm{c}}$ & & $24.0 \pm 3.8$ & $24.3 \pm 3.8$ & $27.6 \pm 3.8^{2}$ & - \\
\hline Gestational week $^{\mathrm{b}}$ & & $12.4 \pm 1.2$ & $12.4 \pm 1.1$ & $30.2 \pm 2.1^{1}$ & - \\
\hline $\begin{array}{l}\text { Total fish } \\
\text { consumption }\end{array}$ & $\begin{array}{l}\geq \text { once a } \\
\text { week }\end{array}$ & $85(58)$ & $57(66)$ & $56(65)$ & 0.835 \\
\hline Marine Fish & $\begin{array}{l}\geq \text { once a } \\
\text { week }\end{array}$ & $63(43)$ & $44(51)$ & $46(54)$ & 0.715 \\
\hline Predatory fish & $\begin{array}{l}\geq \text { once a } \\
\text { week }\end{array}$ & $5(3)$ & $4(5)$ & $4(5)$ & 1.000 \\
\hline Shellfish & $\begin{array}{l}\geq \text { once a } \\
\text { week }\end{array}$ & $19(13)$ & $11(13)$ & $14(17)^{1}$ & 0.467 \\
\hline Freshwater fish & $\begin{array}{l}\geq \text { once a } \\
\text { week }\end{array}$ & $3(2)$ & $2(2)$ & $3(4)$ & 1.000 \\
\hline $\begin{array}{l}\text { Work in a dental } \\
\text { clinic }\end{array}$ & Yes & $4(3)$ & $3(4)$ & $2(2)$ & 1.000 \\
\hline $\begin{array}{l}\mathrm{a}=\text { Given as media } \\
\mathrm{b}=\text { Given as mean } \\
\mathrm{c}=\text { Body Mass Ind } \\
(\mathrm{kg} / \mathrm{m} 2) \\
{ }^{1}=\text { One missing } \\
{ }^{2}=\text { Two missing }\end{array}$ & $\begin{array}{l}\text { due to skew } \\
\text { e to norma } \\
\text { (BMI) giv }\end{array}$ & $\begin{array}{l}\text { distribution (min, } n \\
\text { tribution; } \pm \text { Standar } \\
s \text { body mass dividec }\end{array}$ & $\begin{array}{l}\text { nax) } \\
\text { rd distribution (SD) } \\
d \text { by the square of } t\end{array}$ & the body height & \\
\hline
\end{tabular}


Table II. Regression coefficients (with $95 \% \mathrm{CI}$ in parenthesis) provides the percentage difference in hair-mercury (Hg) concentrations (in $\mu \mathrm{g} / \mathrm{g}$ ) by exposure category.

Total at enrolment $(n=146)$

Participants with follow-up $(\mathrm{n}=86)$

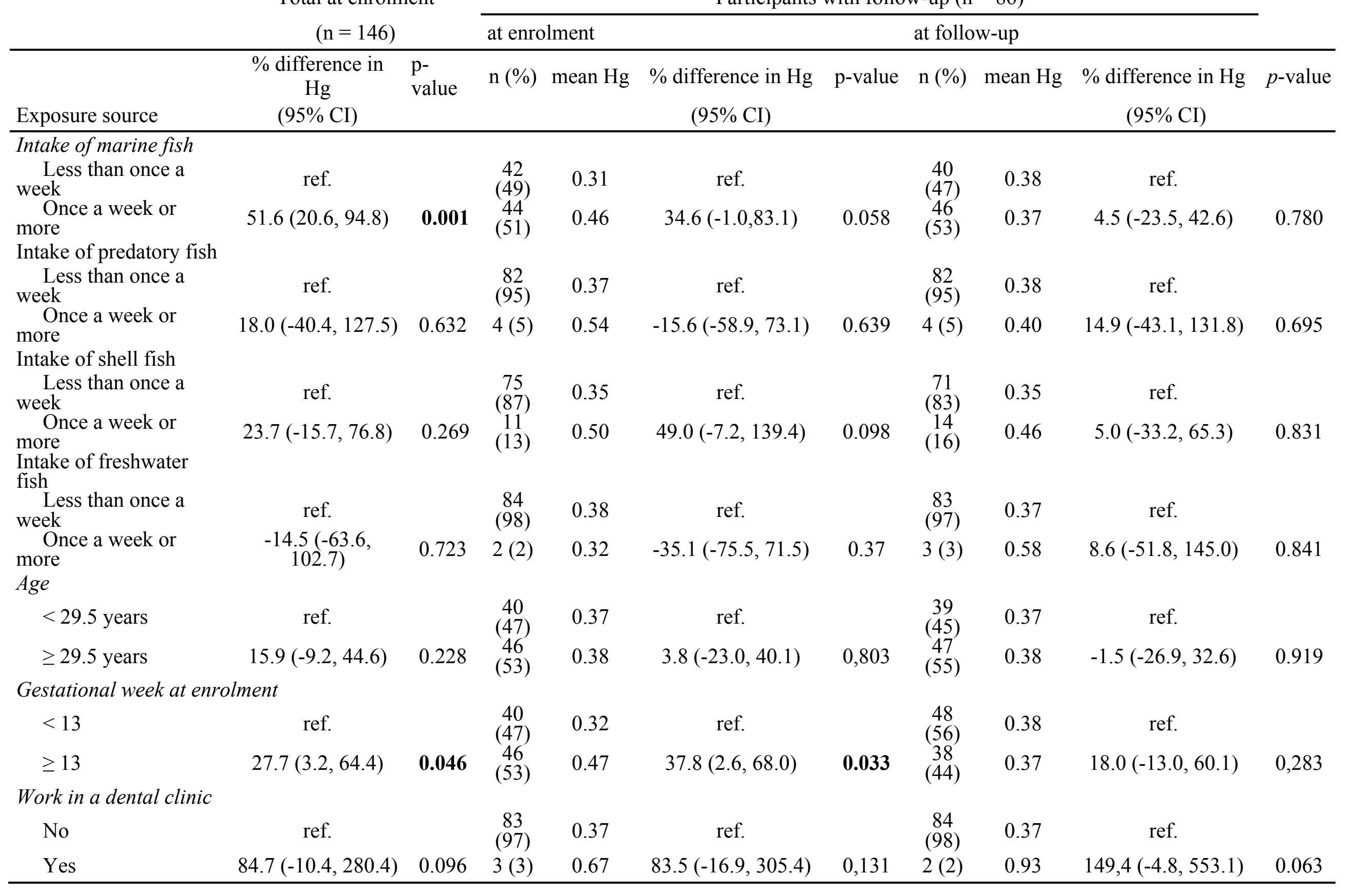


